\title{
RESULTADOS CIENTÍFICOS DO CRUZEIRO DO "BAEPENDI" E DO "VEGA" À ILHA DA TRINDADE
}

Nota preliminar sôbre algumas Algas.

A. Brandão Joly *

Esta nota tem a finalidade de acrescentar novos dados sôbre a distribuição geográfica de algumas algas, especialmente de Chlorophyceas. Obtivemos o material coletado por gentileza do Prof. W. Besnard, Diretor do Instituto Paulista de Oceanografia, a quem somos agradecidos.

A coleta das algas foi feita pelo mencionado Cientista, em MaioJunho de 1950, quando tomou parte em uma expedição oficial às ilhas Trindade e Martim Vaz chefiando os trabalhos oceanográficos. Todo o material foi obtido por dragagens ao largo das ilhas e representa somente a flora de profundidade; nenhuma coleta foi feita no litoral das ilhas.

Além das algas calcáreas e algumas outras, toda a coleção é representada por exemplares fragmentados; isto devido à falta de ajudantes experimentados, à velocidade do navio, de bordo do qual foram feitas as aragagens e à grande distância percorrida em cada dragagem.

A ilha está situada a $20^{\circ} 30^{\circ}$ Lat. S. e $29^{\circ} 22^{\prime}$ Long. W. Gw. e a cerca de $1500 \mathrm{Km}$ afastada do litoral do Estado do Espírito Santo. Entre os espécimens coletados só nos foi possivel identificar os mais caracteristicos devido à falta de material autêntico para comparação.

As identificações estão baseadas principalmente nas descrições do Sylloge Algarum (1) e nos trabalhos de Taylor $(4,5)$. As áreas de dispersão mencionadas, referem-se a Fritsch (2) e a Taylor (4).

(*) DEP. BOTÅNICA. Fac. Fil. Ciênc. Let. Universidade de S. Paulo. 


\section{Fam. CODIACEAE}

HALIMEDA Lamouroux, 1812

H. Opuntia (L.) Lamx.

Comum e de grande área de dispersão. Seg. Taylor (4) referida desde as Bermudas até Rio de Janeiro.

\section{PENICILLUS Lamarck, 1813}

P. Lamourouxii Decaisne

Rara; referida somente para a região das Caraibas (Florida a Venezuela cf. 4). Esta é a primeira ocorrência verificada abaixo do Equador no Oceano Atlântico. Abundante no material.

UDOTEA Lamouroux, 1813

U. Flabellum (E. E Sol.) Howe

Espécie tropical comum (cf. 4) mas referida para o Brasil somente para Cabo Branco no estado da Paraíba.

\section{Fam. VALONIACEAE}

\section{DICTYOSPHAERIA Decaisne, 1892}

D. favulosa (Ag.) Dcne.

Espécie comum, referida para o Brasil como ocorrendo em Cabo Frio. estado do Rio de Janeiro (cf. 5)

\section{ANADYOMENE Lamouroux, 1816}

A. stellata (W.) J. Ag.

Referida para o Brasil somente por coletas feitas ao norte da ilha da Trindade.

(1)

De acordo com Fritsch (2, Mapa I) Dictyosphaeria favulosa não ocorreria no Atlantico Sul e Anadyomene stellata é conhecida entre nós somente do Nordeste do Brasil (veja Mapa I, 1.c.); porém Luetzelburg (3) e mais tarde Taylor (5) já tinham referido a ocorrencia de ambas muito mais ao Sul do que o indicado posteriormente no mapa de Fritsch.

(1) - O autor encontrou a mesma espécie muito mais ao Sul, em Angra dos Reis, Estado do Rio de Janeiro, a $23^{\circ}$ Lat. S., na mesma localidade já assinalada por Luetzelburg (1. c. II pg. 230) em 1922-1923. 
Fritsch (1.c.) apresenta também a área de dispersão conjunta de ambas as espécies acima mencionadas, como sendo limitada à região das Caraibas.

Agora com este achado amplia-se de muito a área de dispersão conjunta de ambas as espécies.

\section{SUMMARY}

This preliminary paper gives new informations concerning occurrence and geographical dispersal of some Chlorophyceae collected at TRINDADE ISLAND $\left(20^{\circ} 30^{\circ}\right.$ Lat. S. and $29^{\circ} 22^{\prime}$ Long. W. Gw.). The following species are considered:

Halimeda Opuntia (L.) Lamx.

Penicillus Lamourouxii Dcne.

Udotea Flabellum (E. \& Sol.) Howe.

Dictyosphaeria favulosa (Ag.) Dcne. Anadyomene stellata (W.) J. Ag.

\section{BIBLIOGRAFIA}

1 - DE TONI, J. B. - Sylloge Algarun I, 1. Patavii. 1889.

2 - FRITSCH, F. E. - The structure and reproâction of the Algae. I-II. Cambridge 1935-1945.

3 - LưtZelburg, P. von - Estudo Botanico do Nordeste. Insp. Fed. Obras Contra as Seccas-Min. Viaç. Ob. Publ. Public. 57 ser. I, A. vol. 2 e 3 1922-1923. Rio de Janeiro. Brasil.

4 - TAYLOR, Wm. R. - Caribbean Marine Algae of the Allan Hancock Expedition 1939. Report n..$^{\circ}$ 2. 1942. Los Angeles, California.

5 - "A synopsis of the marine algae of Brasil. Rev. Alg." - V, 3-4: 279-313. Paris 1931. 